\title{
LA OBRA DE BALTASAR GRACIÁN EN POLONIA
}

\author{
TERESA EMINOWICZ \\ Universidad Jaguellónica de Cracovia (Polonia)
}

\begin{abstract}
El cuarto centenario del nacimiento de Baltasar Gracián es un momento idóneo para hacer un resumen de la suerte de la obra del pensador y escritor, uno de los más eminentes representantes del Barroco español, harto conocido en la Europa Occidental aún en vida. Para analizar la suerte de su obra en Polonia hay que tener en cuenta el contexto político-cultural del siglo XVII y los siglos sucesivos. Este planteamiento nos permitirá ver a Gracián en sus verdaderas proporciones respecto a otros escritores españoles de la época y su recepción en Polonia a lo largo de los cuatro siglos posteriores.
\end{abstract}

Las relaciones políticoculturales entre Polonia y España a partir del siglo $\mathrm{XVI}^{1}$ se hicieron bastante intensas y estrechas. Entre otras razones de esta intensificación encontramos los enlaces dinásticos con los Habsburgo tanto por parte de Polonia - cuyos reyes se casaban con las princesas austríacas- como por parte española con el advenimiento de la Casa de Austria en España. Las estancias de los embajadores de los respectivos países se hacen casi permanentes. En 1564 la Compañía de Jesús llega a Polonia y abre sus primeras casas en Polonia y Lituania, fundando colegios. En la primera época varios jesuitas españoles llegan a Polonia y a menudo ocupan puestos importantes en la corte y en las casas de los magnates seglares y eclesiásticos. Estas animadas relaciones repercuten en la creación literaria española, dándose el caso de la repetida aparición de protagonistas polacos en obras de la época. La moda española llega hasta Polonia como a otros países europeos. Sin embargo, todos estos fenómenos no significan que el idioma y el conocimiento de la literatura española se difundan universalmente. Tan sólo en unos pocos focos situados en la corte y las residencias de los grandes fueron la lengua y cultura españolas conocidas. Aun

\footnotetext{
1 Véase mi estudio: Las relaciones político culturales entre Polonia y España en la época de Felipe II, en Felipe II (1527-1598) Europa y la Monarquía Católica, t. IV, Literatura, cultura y Arte, coordinador V. Pinto Crespo, director J. Martínez Millán, Ed. Parteluz, S.L., Madrid, 1998, pp. 89-99.
}

Rlit, LXIV, 127 (2002), 209-218 
los viajes de los polacos al otro lado de los Pirineos ${ }^{2}$ no contribuyeron en gran escala a la difusión del conocimiento de lo español en Polonia. Los diarios manuscritos de viaje con observaciones de gran interés permanecieron escondidos en las bibliotecas de las familias de aquellos curiosos viajeros.

La moda española en el vestir, algunas costumbres, el vino en las mesas de Polonia y, además de esto, la presencia de algunas palabras españolas en nuestra lengua fueron sólo síntomas superficiales y no condujeron a un interés claro por la literatura española. A pesar de que los embajadores, eclesiásticos y viajeros traían en su equipaje obras españolas, todas ellas permanecieron en el anonimato de las estanterías de las bibliotecas durante largo tiempo. Las primeras traducciones de obras españolas, salvo algunos casos excepcionales, aparecen en la segunda mitad del siglo XVI. Son los textos devotos y los de los grandes místicos españoles. Guía de pecadores de Fray Luis de Granada, fue traducida por Stanislaw Warszewicki (1570), quien contribuyó a la llegada de la Compañía de Jesús a Polonia. En la introducción de su versión dice que en Polonia no hay textos devotos para que los creyentes puedan profundizar su fe a través de la lectura y no apartarse de la ortodoxia en los tiempos del proselitismo de otras sectas. Las obras de Gracián, demasiado profanas, no eran convenientes para la política contrarreformista en Polonia. Hay que tener en cuenta que las autoridades de la Compañía miraban con recelo la obra del Padre Baltasar. Dado que su publicación coincidió con los ataques contra la Compañía es de entender que a los jesuitas de Polonia no les interesase la traducción de sus obras.

Es significativo que la mencionada traducción de Fray Luis de Granada se hiciera de la versión italiana, probablemente la de Pietro Lauro Mondonese, con la que tiene muchas similitudes. Las tempranas traducciones del español al polaco se hacían del latín o del italiano, mucho más conocidos en Polonia. Sólo en el siglo XVIII empiezan a hacerse del francés y en el siglo XIX el alemán empieza a servir de base para las traducciones al polaco. Las traducciones directas del español se hacen sólo en el siglo XX. A pesar de la existencia de muchos libros españoles en las bibliotecas de Polonia, en el siglo XVII se hacen pocas traducciones. Cuando Gracián empieza a publicar sus obras en España, en Polonia la situación no es propicia para llevar una labor de este tipo ya que el país está en guerra casi permanente: Moscovia, Suecia, y la progresiva rebelión de los cosacos. El siglo XVIII, siglo de Ilustración es un siglo propicio para las traducciones a pesar de que la monarquía ya no tiene el poder de antes y

\footnotetext{
${ }^{2}$ A. MĄCZAK, Peregrynacje, wojazie, turystyka, Varsovia, 1984. A. SAJKOWSKI, Opowieści misjonarzy, konkwistadorów, pielgrzymów i innych świata ciekawych, Poznań, 1991.
} 
la progresiva decadencia política terminará con el reparto de Polonia entre Rusia, Prusia y Austria. La fundación del primer ministerio de educación contribuye a desarrollar un programa de educación cívica. En este contexto la obra moralizadora de Gracián fue interesante. En aquel siglo Francia se vuelve modelo para otros países y el francés se convierte en una lengua popular. Los intelectuales de Polonia miraban hacia Francia y en aquel país la obra de Gracián tenía gran éxito. Es por ello que sólo en el siglo XVIII la obra del jesuita español llega a Polonia. Las traducciones gracianescas se hacen de las versiones francesas por falta de conocimiento de la lengua de Cervantes.

La llegada de las obras de Gracián a Polonia es bastante tardía y sólo dos obras fueron traducidas integralmente, mientras que las demás existen en versiones fragmentarias. La primera de ellas se publicó en Wilno (Vilna), en Lituania, donde existía un centro muy importante de la Compañía de Jesús. En 1762 se publica la traducción de El Discreto - Czlowiek uniwersalny $z$ francuskiego przełozony. En 1765 aparece la segunda edición por lo que podemos suponer que si la primera edición se agotó fue debido a un cierto éxito. El traductor, A. Brzostowski era canónigo de la catedral de Vilna. Para su traducción escogió la versión francesa del jesuita J. de Courbeville, publicada en París en 1723 con el título L'homme universel, traduit de l'espagnol de Baltasar Gracien. La traducción francesa de Courbeville fue criticada por el gracianólogo contemporáneo, A. Coster. El título mismo provocó protestas ya que no refelejaba la esencia del tratado.

Brzostowski dedicó su traducción a Jerzy de Wandalin Mniszka, mariscal de la corona y general de la Gran Polonia, considerando a éste la encarnación del hombre universal: lo que Gracjan (sic) en su obra adscribió, tú lo enseñas suficientemente en ti mismo. El traductor polaco omitió el prólogo de Courbeville pero la traducción es fiel e imita el estilo del francés. J. Morawski, hispanista polaco, comentando la traducción ${ }^{3}$, cita como una curiosidad la mención a Don Quijote: particularmente los jactanciosos no se pueden comparar con el héroe de Cervantes, que fue por lo menos valeroso. Porque, refiriéndome a los convencidos de su valor, los Quijotes de hoy tienen todo lo censurable en él, es decir que fue quimérico, y no poseen lo que fue plausible en él, el valor ${ }^{4}$.

En el prólogo, Brzostowski explica el porqué de haber escogido esta obra de Gracián. Dice que: He encontrado en este autor un pensamiento hermoso, altos sentimientos y sentencias, tanto gusto y provecho, que me pareció que cualquiera deseoso de pulir y perfeccionar su entendimiento, costumbres y juicio puede servirse del libro de Gracjan sobre el hombre

\footnotetext{
${ }^{3}$ J. MoRAWSKI, Dwaj moralisci hiszpanscy, Quevedo y Gracián, w szacie polskiej, Poznan, 1934.

${ }^{4}$ Ibídem.
} 
universal como guía en esta materia... pocas obras de esta índole se puede encontrar. Subraya que hay pocos críticos que sepan decir la verdad sin improperios. Después de Esopo sólo Gracián supo usar los apólogos y fábulas llenos de una viva y fuerte imaginación. Alaba además la riqueza de pensamiento para educar al hombre que encierran estas breves palabras. Según Brzostowski, así Amelot valora a Gracián ${ }^{5}$.

El traductor polaco valora en el prólogo, la obra y el estilo e indica la utilidad del tratado como guía de comportamiento apoyándose en la opinión de Amelot de la Houssaie, aunque sin embargo, traduce de la versión de Courbeville. Es una traducción fiel, que no carece de equivalentes acertados, y si le faltan las palabras usa la forma francesa polonizada (exaggeration = exaggeracya; ne distingue point $=$ nie dystyngwuje). $\mathrm{A}$ veces, no obstante, no capta exactamente el sentido del término francés <mécontent> se traduce como <contento $>$. He aquí algunas pruebas de la libertad en la traducción por falta de comprensión o de vocablos. Si añadimos a eso la inexactitud de la versión francesa se ve cómo la traducción puede alejarse del original.

La segunda obra de Gracián traducida al polaco fue el Oráculo manual $o$ arte de prudencia, traducido por A. Brodowski, jesuita, impreso en Sandomierz en 1764. Es la traducción de la versión francesa de Courbeville de 1730 publicada en París. En el título de la traducción polaca encontramos una información sorprendente, a saber, que las máximas fueron escogidas por Vicente de Lastanosa, príncipe de Nochiera (sic). Ya J. Morawski se pregunta de dónde Brodowski sacó la información que estos dos mecenas y amigos de Gracián fueron una sola persona. Courbeville no menciona a Nocera sino que el traductor polaco obtuvo esta información de otra fuente, lo que no nos sorprende tratándose de un jesuita ya que éste pudo tener noticias sacadas de los archivos de la Compañía.

J. Morawski constata que en la versión de Brodowski se nota el estilo <jesuíticio> de los tiempos del rey Estanislao Poniatowski. Este estilo se caracteriza por una expresión fluida y elegante. La máxima CCC es difícil de traducir. En español, tres eses hacen dichoso: santo, sano y sabio. Brodowski dice: las tres eses (según lenguas extranjeras) nos hacen felices: sainteté, santé, sagesse (en francés) es decir santidad, salud y sabiduría. Para comparar cito la versión moderna de dos distintos traductores polacos; tres dones condicionan la felicidad humana: salud, juicio, santidad (Gajewicz) y Hay tres fuentes de felicidad: santidad, salud y sagacidad. Los dos renunciaron a las tres eses del original.

La siguiente traducción polaca del Oráculo es la de 1802, publicada en Cracovia por Wacław, conde Sierakowski, párroco de la catedral de Cracovia. El autor hizo su versión de la traducción francesa de Amelot de la

\footnotetext{
${ }^{5}$ B. GRACYAN, Człowiek uniwersalny, trad. P.X. Brzostowski, Wilno, 1762.
} 
Houssaie publicada en París en 1684, anterior a la traducción de Courbeville. J. Morawski, comentando esta traducción, considera que la versión de Amelot es peor que la de Courbeville por ser demasiado literal, con muchos hispanismos y no siempre fiel al original. Courbeville más bien parafraseaba, por lo que el pensamiento del jesuita español está mejor reflejado, y resulta más elegante que en la traducción de Amelot.

El mérito de Amelot radica en las notas, a veces sacadas de las obras del mismo Gracián. Sierakowski tradujo todas las explicaciones de Amelot y casi todo el prólogo, no citándolo, sin embargo. Omitió solamente la parte referente a otras obras de Gracián. El texto de Amelot, poco claro de por sí, se hace a veces incluso más oscuro, hasta incomprensible, según Morawski, debido a una mala interpretación de las palabras por parte de Sierakowski. Por ejemplo <une boussole> (brújula) del texto francés se traduce como <hucha $>$ al polaco o <port de l'Excellence $>$ se convierte en $<$ los salones de los magnates $>$. El texto de Sierakowski contiene también varios galicismos y barbarismos. La traducción de Courbeville-Brodowski es mucho mejor que la de Amelot-Sierakowski. Parece que la mala traducción no es solamente consecuencia de un modelo malo sino que Sierakowski carece de talento literario y además no conoce suficientemente el francés.

En cuanto a las traducciones modernas, aparecieron dos al mismo tiempo en 1949. Una en París hecha por Bohdan Gajewicz, otra por Stanisław Łoś en Lublin. La de París no se difundió en Polonia por las dificultades en los contactos con Occidente para los países del bloque comunista. El único ejemplar que se hallaba en la biblioteca Jaguellónica de Cracovia llevaba en la ficha del catálogo la abreviatura $<$ res $>$, lo que significaba que no era accessible al público general, sino que estaba reservada sólo para personas autorizadas por el mero hecho de haberse impreso en París.

La traducción publicada en París está preparada con esmero. Reproduce el único retrato conocido del autor. Está hecha a partir de la traducción de Amelot, edición anotada de 1692, con prólogo y aclaraciones finales del traductor polaco. El título es Breviario diplomático y el apellido del autor español, como en las versiones polacas anteriores, está polonizado pero con la ortografía actualizada, o sea, en vez de la forma más antigua Gracyan encontramos ahora Gracjan. Esta última es la que existe en todos los textos polacos en los que aparece el apellido del escritor. Son, por lo general, sus máximas citadas en distintos medios de difusión. Gajewicz explica el porqué del título: el tamaño del libro, su formato elegante con los bordes de las páginas dorados, su hallazgo casual entre los libros antiguos de un vendedor (bouquiniste) de las orillas del Sena en París, la condición eclesiástica del autor y la utilidad de la lectura diaria le sugirieron este título.

El prólogo contiene la biografía del jesuita que termina con la siguiente constatación: Muere en un lugar apartado en Tarazona, deportado ahí 
por el general alemán (aunque general de jesuitas) llamado Goswin Nickel. Sabemos que en Tarazona desempeñó importantes cargos, descubriendo así que no estuvo recluído en una cárcel penitenciaria. Gajewicz cita el fragmento de la Historia de la Compañía de Jesús de Crétineau-Joly de 1846 dedicado a Gracián, muy favorable para el escritor. Dice, entre otras cosas, que sus obras son devoradas por el público, lo que acredita el éxito de Gracián en el siglo XIX. El libro termina con el índice temático de las máximas y notas del traductor llamadas <minucias>. La primera es un esbozo de la suerte de la obra de Gracián en Europa. Subraya que en Polonia entre 1802 y 1949 no se publicó ninguna traducción del escritor español. En otras <minucias> habla de los estudios de Gracián, de su familia, de su labor didáctica en los colegios y de su obra. Encontramos en otra <minucia> el comentario de la obra de Gracián y la explicación del título de la traducción. Nos enteramos también de cuáles fueron los modelos e influencias europeas del conceptista español. Al emprender la labor de traducción, Gajewicz no quiso traicionar la personalidad del autor español, reproduciendo fielmente sus conceptos y todo ello con un estilo elegante y claro, por lo que se puede decir que es una traducción lograda.

El mismo año aparece en Lublin, en Polonia, la traducción del Oráculo hecha por Stanisław Łoś. Esta edición tampoco pudo contribuir a la difusión de la obra ya que consta de sólo mil ejemplares. El traductor confiesa que le ayudaron mucho la traducción francesa de Amelot de la Houssaie y la alemana de Schopenhauer sin decir, sin embargo, si se ha servido fundamentalmente del original español. Supongo que pudo valerse de la versión italiana ya que por las palabras españolas citadas por él se nota la interferencia del italiano como por ejemplo en <il padre de la Victoria>. Łoś declara que la traducción no es literal, aunque el traductor - en la medida de lo possible - intentó mantener el estilo del autor con tal que el pensamiento de Gracián no se deformara al pasar al polaco. El título de esta traducción, Wyrocznia podręczna es el primero que corresponde a la primera parte del título gracianesco, aunque omite la segunda parte Arte de prudencia. El recurrir a varias traducciones preparando la versión polaca es testimonio de la seriedad con que trató Łoś su labor de traductor.

En el prólogo — Siglo y clima de Baltasar Gracián- Łoś dice que por suerte tenemos pocas noticias de la vida y personalidad del autor, con la excepción de las que se pueden recoger de sus obras y las escuetas informaciones de las crónicas de la Compañía, ya que gracias a ello el autor queda en la sombra y podemos concentrarnos exclusivamente en la obra. No coincido en este punto con Łoś, ya que él dice que de su obra se extrae alguna información biográfica y yo considero que ninguna en absoluto.

En este esbozo histórico se subraya que las provincias de la Península defendían con celo sus privilegios y particularidades frente a los reyes y 
$<$ banda de funcionarios castellanos $>$. En Cataluña y Aragón la defensa llevó a la guerra civil. Sin embargo, hay una diferencia; mientras Cataluña se oponía al rey y Castilla buscando auxilio en Francia, Aragón nunca se opuso a la figura del rey que era a la vez rey de Aragón. Gracián dio personalmente testimonio de la lealtad al rey en el sitio de Lérida. Como se sabe, Gracián era partidario de la unidad de la Península creada gracias a la sabiduría de Fernando el Católico, modelo de político, según el jesuita.

Łoś subraya que el escritor español se interesaba por el hombre como fenómeno social, que era sociólogo por vocación, mucho antes de la formación de la sociología, y fue ante todo psicólogo de la sociedad. Considera que El discreto traza el modelo de confidente-consejero. Supongo que se ha visto influido por el significado de la palabra homónima polaca (dyskretny) que identifica a un hombre que se queda en la sombra (éste es el papel del confidente y consejero), mientras que el modelo de Gracián es el de un hombre que quiere adquirir fama y destacar en la corte. En cuanto al estilo de Gracián, el traductor polaco subraya que su conceptismo fue moderado.

Comentando la obra traducida, Łoś da cuenta de la atmósfera de desengaño, escepticismo y resignación que emana del libro por la situación vital en la que se encontraba el escritor - hombre juicioso y ambiciosoprivado de la posibilidad de desempeñar un papel importante. Gracián es conciente de que tal situación está motivada por su nacimiento y estado eclesiástico, y aunque sufría por ello, no piensa en rebelarse ya que considera esto como consecuencia del orden natural de las cosas. Además de las razones particulares estuvo también bajo la influencia del ambiente general de la época, caracterizado por el desengaño.

El traductor se embarca en un comentario, bastante controvertido, sobre la situación de la España de Gracián y su valoración por los historiadores decimonónicos. Aquellos historiadores opinaban que desde el advenimiento al trono de Felipe II España vivió una época de derrotas e infortunios; según Łoś, era un vaticinio ex post por razones nacionales, ideológicas y sobre todo religiosas, ya que los historiadores del siglo XIX eran muy negativos frente a la España de los Habsburgo. Al parecer del comentarista polaco fue al revés: la España de la primera mitad del siglo XVII fue la monarquía más grande y poderosa del mundo de entonces; además desde cierto punto de vista, fue la mejor organizada en la Europa de entonces ya que fue la única que evitó la guerra civil y los disturbios internos. Estos desastres ensangrentaron la Francia de Luis XIII y la de la minoría de Luis XIV, del mismo modo que devastaron Alemania durante la Guerra de los Treinta Años. Ya que la intolerancia significó evitar la guerra civil, es difícil juzgar negativamente a los dirigentes por ello. No se puede acusar, pues, a los monarcas españoles de haber adoptado estas medidas. La base del poder español fue el ejército, la cultura y la diplo- 
macia. No extraña, pues, que los coetáneos no se dieran cuenta del desarrollo de la enfermedad del inmenso organismo; su intensidad y su carácter no eran tan alarmantes como lo presenta la historiografía. Esta constatación niega lo que dijo antes sobre el ambiente general caracterizado por el desengaño. Es difícil aceptar esta interpretación. Varias obras de diferentes autores españoles de la primera mitad del siglo XVII traducen la inquietud de los más lúcidos por el porvenir del país. Gracián, hijo de una nación fuerte, consideraba que el hombre juicioso debe contentarse con ser hombre idóneo y útil en el puesto que consiga, ésta es la lección del jesuita según el traductor polaco.

En la versión comentada no hay notas. El estilo es claro y se ve que el traductor observa los principios del autor español que es partidario de una expresión concisa. Si comparamos este texto con la traducción de Gajewicz parece menos fluido, aunque la lengua, a veces, resulta más cruda. La II máxima, por ejemplo, en la que encontramos la expresión <necios> en español, Łoś llama <mentecatos> mientras que Gajewicz usa el eufemismo <desafortunados>. La frase gracianesca de la máxima III, Es el recatado silencio sagrado de la cordura la encontramos en la traducción de Gajewicz, badasa en la versión de Amelot, reproducida de la forma siguiente: El silencio es el santuario de la cordura, mientras que Łoś la traduce como: El pensar prudente es el templo de la cordura. Se nota que los dos entendieron <el sagrado> como lugar de culto en lugar de refugio de la cordura. Sin embargo, las dos versiones se leen sin esfuerzo y la idea del autor nunca está expresada de manera poco clara. Que sea exacta es otra cuestión. El mérito de los dos traductores es haber hecho accesible el texto del siglo XVII con una expresión elegante. Por desgracia, la edición de Lublin cuenta con sólo 1000 ejemplares con lo que su difusión es muy limitada.

D. Kucała en el artículo dedicado a las traducciones polacas del Oráculo manual considera que el excepcional éxito de esta obra comparado con las obras de otros escritores españoles de la época se debe a su difusión en Francia y Alemania. Comentando la versión de Gajewicz señala que el traductor actualiza la lengua al utilizar vocablos coloquiales y expresivos como por ejemplo palabras pertenecientes al vocabulario deportivo para mostrar la vida como constante lucha. Los fragmentos con una sintaxis complicada pueden ser estilización barroca. La estudiosa constata que el mérito de la traducción de Gajewicz son las notas y varias estrategias de traducción. Resumiendo, opina que la versión de Gajewicz es más amena, viva e interesante ${ }^{6}$.

${ }^{6}$ D. KUCAEA, $<$ W jakim stopniu tłumacze dawnych tekstów <stosują się do ducha czasu $>$ ? Na marginesie przekładu Wyroczni podrecznej Baltasara Graciána> en: Miedzy oryginałem a przekładem (Entre el original y la traducción) IV, Cracovia, 1998, pp. 285-290. 
En 1997 la versión de Łoś fue reimpresa en Lublin pero sin cambios sustanciales. Sólo el apellido del autor es corregido, corresponde a su versión española, pero los demás apellidos españoles en el prólogo no fueron corregidos. Los errores en cuanto a la biografía del autor no se corrigieron; su padre aparece como jurista. Tampoco se enmendó el comentario sobre la historia de aquellos tiempos. Gracián mereció el título de <padre de la victoria> durante la guerra civil, mientras que en el prólogo se dice que gracias a la política de los reyes españoles la monarquía evitó la guerra civil. España también estuvo involucrada en la Guerra de los Treinta Años, y aunque ésta no se desarrolló en su territorio también sufrió sus consecuencias, sobre todo económicas y humanas.

Nadie se dedicó a comentar la traducción del título. En las versiones de los siglos pasados los autores se contentaron con indicar la forma <máxima> -indicando el propósito de formar a un hombre avisado, omitiendo la segunda parte del título, importante, que define en qué consiste el éxito, en dominar un arte.

A pesar de la poca difusión de las máximas de Gracián en forma de libro por las razones antedichas, hay que constatar que a veces sus máximas están citadas aun en los mass media polacos.

Otras obras del jesuita español no fueron traducidas al polaco. Ahora se prepara una traducción de El Héroe y El Discreto con motivo del cuarto centenario del nacimiento del escritor. Nadie se atrevió a traducir $E l$ Criticón, quizás por la dificultad del texto. En cuanto a Agudeza y arte de ingenio no se traduce porque los teóricos que se dedican al estudio de este tipo de tratados barrocos consideran que el de Gracián es poco original.

Sorprendente es la falta de estudios sobre Gracián en Polonia. Salvo algunas menciones a otros textos, Gracián es sobre todo citado como autor de Agudeza y arte de ingenio con algunos fragmentos del tratado. No interesa el escritor ni a los teóricos ni a los críticos literarios a lo largo de los siglos. Esta falta de interés es sorprendente teniendo en cuenta que Gracián es uno de los escritores del barroco español más tempranamente traducido, con varias traducciones, reimpresas algunas de ellas y siendo uno de los pensadores con mayor vigencia en nuestros días por la modernidad de sus ideas. 


\section{RESUMEN}

\section{La obra de Baltasar Gracián en Polonia, por Teresa Eminowicz}

Sólo dos obras de Baltasar Gracián fueron traducidas enteramente al polaco. En 1762 El Discreto fue publicado en Vilna con su segunda impresión en 1765. El traductor, A. Brzostowki, se apoyó en la versión francesa de Courbeville de 1723. La segunda traducción es la del Oráculo manual (1764). La traducción de Courbeville fue también su fuente. La segunda traducción de la misma obra se publicó en Cracovia en 1802. El traductor, el conde Sierakowski, usó también como base la versión francesa de Amelot de la Houssaie de 1684. Dos traducciones modernas del Oráculo son de 1949. Bohdan Gajewicz publica en París el Breviario diplomático, de la versión de Amelot de 1692, Stanislaw Los en Lublin declara haber consultado la versión de Amelot y la de Schopenhauer sin mencionar la original española.

\section{SUMMARY}

Only two works of Baltasar Gracián were translated into Polish entirely. In $1762 \mathrm{El}$ Discreto was published in Vilna, a second printing followed in 1765. The translator, A. Brzostowski, used the French translation of J. de Courbeville, published in 1723 in Paris. The second work of Gracián translated in Polish, the Oráculo manual o arte de prudencia, appeared in 1764. The translator, a Jesuit A. Brodowski, also used de Courbeville as his source. A second translation of the Oráculo appeared in Cracov in 1802. The translator, Count Sierakowski, used the French version of Amelot de la Houssaie published in Paris in 1684, prior to the 1730 work of de Courbeville.Two modern translations of the Oráculo, appeared simultaneously in 1949. One in Paris, by Bohdan Gajewicz, the other one in Lublin, by Stanislaw Los. Gajewicz based his translation on Amelot's 1692 annotated edition. Titled Diplomatic Breviary, the book contains Gracián's biography, thematic index and translator's notes. Stanislaw Los, quotes two important sources for his translation, Amelot and Schopenhauer but does not reveal whether he also used the Spanish original. 